\title{
MPPT with Current Control for a PMSG Small Wind Turbine in a Grid-Connected DC Microgrid
}

\author{
Daniel Zammit, Cyril Spiteri Staines, Alexander Micallef, Maurice Apap
}

\begin{abstract}
This paper presents a Maximum Power Point Tracking (MPPT) system for a small wind turbine (SWT) connected to a DC Microgrid under grid-connection conditions. The system consists of a Permanent Magnet Synchronous Generator (PMSG) driven by a SWT which is interfaced to the DC microgrid through a rectification stage and boost converter. The proposed MPPT system is based on the relationship between the DC link power and voltage, which are used to obtain the required inductor current in the Boost converter to provide maximum power output at all wind speeds. The MPPT system, the Boost converter and current control are explained in detail. Simulation of the system operating under varying wind conditions is presented, showing the performance of the developed MPPT algorithm.
\end{abstract}

\section{INTRODUCTION}

Small wind turbines (SWT) are defined as turbines which do not exceed $100 \mathrm{~kW}$ and are mainly found installed close to inhabited areas where large scale wind turbines cannot be erected. In countries where high wind speeds are common, installation of SWT in remote sites (or for off-grid applications) are a viable option even though they have high installation and maintenance costs. Such sites normally consist of a small group of buildings located relatively close to each other, which makes the application of a microgrid system very attractive for their electricity supply. A microgrid system consists of a cluster of generation sources (such as photovoltaic, wind turbines and even fuel based generators) and electrical loads which can function both connected to the main electrical grid as well as independently from the supply network. The microgrid's control aims at maintaining a constant voltage under all operating conditions.

There exist two types of microgrids, mainly; AC and DC. An attractive aspect of microgrids is the ability to operate both in grid-connected mode as well as in islanded mode. In grid-connected mode the microgrid is connected through a coupling point to the electrical grid, while in islanded mode the microgrid is operated in an autonomous way disconnected from the electrical grid. In this paper, the connection of a SWT to a grid-connected DC microgrid shall be discussed. DC microgrids offer a number of advantages, such as, lower conversion losses (fewer DC to AC or vice-versa conversions), no synchronisation, phase or frequency issues (as present in AC microgrids), and also independence from voltage sags, dips, and other power quality issues occurring on the electrical AC grid side.

Daniel Zammit, Prof. Cyril Spiteri Staines, Dr Alexander Micallef and Dr Maurice Apap are with the Department of Industrial Electrical Power Conversion, University of Malta, Msida, MSD 2080, Malta (e-mail: daniel.zammit@um.edu.mt, cyril.spiteristaines@um.edu.mt, alexander.micallef@um.edu.mt,maurice.apap@um.edu.mt).
The most common configuration for SWT grid-connected systems of powers less than $20 \mathrm{~kW}$ normally consist of a high pole pair permanent magnet synchronous generator (PMSG) feeding a three phase rectifier followed by a boost converter and a grid-connected single phase AC inverter. When incorporating a SWT to a DC microgrid, the grid-connected inverter can be omitted, thus decreasing the power conversion system cost by more than half, while at the same time increasing the efficiency of the overall system. The most critical and complex part of the standard AC gridconnected system is the control of the boost converter which is used to regulate the voltage amplitude at the terminals of the PMSG allowing for maximum power transfer. Many WT manufacturers provide a wind turbine power curve to be used for the MPPT control which is normally inbuilt in the gridconnected inverter. However unfortunately this characteristic can be inaccurate resulting in poor MPPT operation. In addition, the pre-programmed characteristic is fixed and hence does not cater for changes which occur over the years. Thus it is recommendable that the MPPT for wind based systems should either be adaptive [1] or independent of the WT characteristic [2,3]. There are three types of MPPT systems in SWTs [2,4]:

1. Power Curve Characteristic Control: requires accurate knowledge of the turbine parameters and requires power and rotational speed measurement

2. Optimal Tip Speed Ratio Control $\left(\lambda_{\text {opt }}\right)$ : requires knowledge of $\lambda_{\text {opt }}$, wind speed and rotational speed.

3. Perturbation and Observation (incremental MPPT) Control: which requires no knowledge of the turbine characteristics and needs power measurement (and in some cases speed measurement).

The first two methods have got a better dynamic response making them suitable for situations of rapid wind variations. On the other hand, the third method is parameter independent, simple to implement and can be applied more to a wide range of different types of SWTs.

This paper proposes an incremental MPPT control methodology for direct connection of a 5kW SWT to a DC microgrid system, which includes current control. An incremental MPPT system covered in [5] was based on the direct variation of the duty cycle of the Boost converter according to the change in the DC link power. In this proposed MPPT algorithm the variation is made in the current according to the change in the DC link power. This current is used as the reference to a Proportional-Integral (PI) controller which controls the Boost inductor current, providing more controllability and robustness to the system. 
The paper is organized as follows. Section II gives an introduction on wind energy conversion. Section III shows the considered system model and describes the electrical conversion modelling and the MPPT algorithm. Simulation results for varying wind conditions are presented in Section IV.

\section{BASICS OF WIND ENERGY CONVERSION}

The power available in a wind stream $P_{\text {air }}$ is given by [6,7]:

$$
P_{\text {air }}=\frac{1}{2} \rho A V_{w}^{3}
$$

where $P_{\text {air }}$ is the power available from the wind [W], $\rho$ is the air density [kg/m3], $A$ is the cross-sectional area of the stream [m2] and $V_{w}$ is the free wind velocity [m/s]. This power cannot be completely extracted and the conversion efficiency is dependent on the power coefficient $C_{P}$. The power coefficient expresses the ratio between the extracted power $P_{w}$ and the available power $P_{a i r}$ as defined by (2).

$$
C_{P}=\frac{P_{w}}{P_{a i r}}
$$

$C_{P}$ can have a maximum of 0.593 , known as the Betz limit. It is a function of two variables: the blade pitch angle $\beta$ and the tip speed ratio $\lambda . \lambda$ is defines as:

$$
\lambda=\frac{\omega_{r o t} R}{V_{w}}
$$

where $R$ is the radius of the rotor $[\mathrm{m}]$ and $\omega_{\text {rot }}$ is the rotational speed of the rotor [rad/s]. Hence, the power extracted by the rotor of a wind turbine is given by:

$$
P_{w}=\frac{1}{2} \rho A V_{w}^{3} C_{P}(\beta, \lambda)
$$

In the case of the SMT, the pitch angle is fixed, thus $C_{P}$ is solely a function of the tip speed ratio $\lambda$. A typical $C p-\lambda$ curve for a horizontal axis three bladed wind turbine is shown in Fig.1.

$$
C p-\lambda
$$

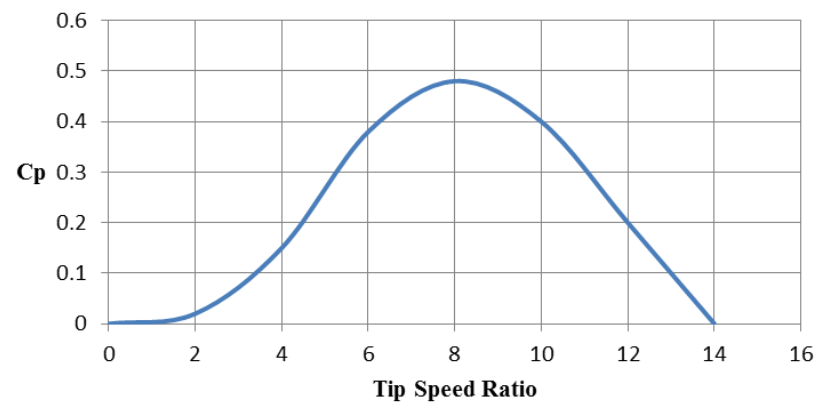

Figure 1. Typical $C p-\lambda$ curve for Three Bladed WT.

By controlling the rotational speed $\omega_{\text {rot }}$ of electrical generator, the tip speed ratio can be adjusted to maximize the $C_{P}$. However as shown in Fig. 2, the maximum power operation point depends also on the wind speed. For every different wind speed there is a different optimal tip speed ratio. By driving the electrical generator with variable speeds, maximum power extraction can be achieved at all wind speeds.

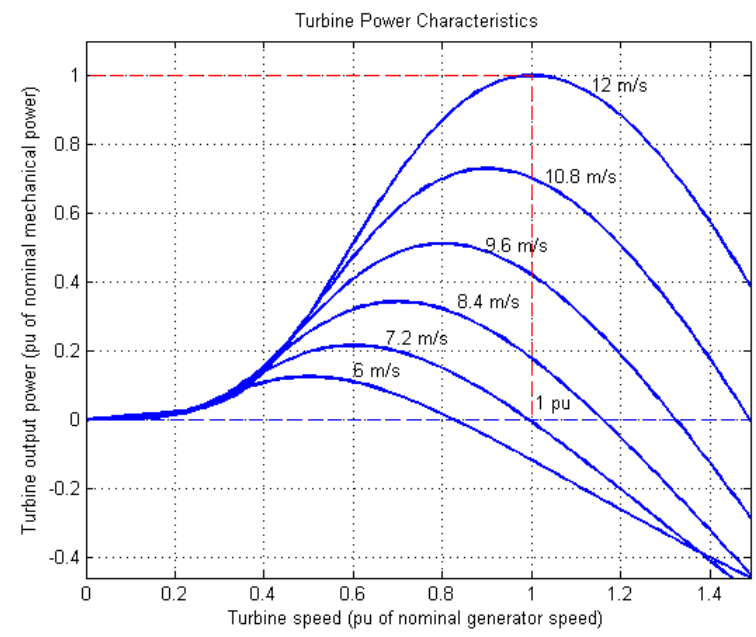

Figure 2. Normalised Extracted Power Curves for Wind Turbine.

\section{SYSTEM MODELLING}

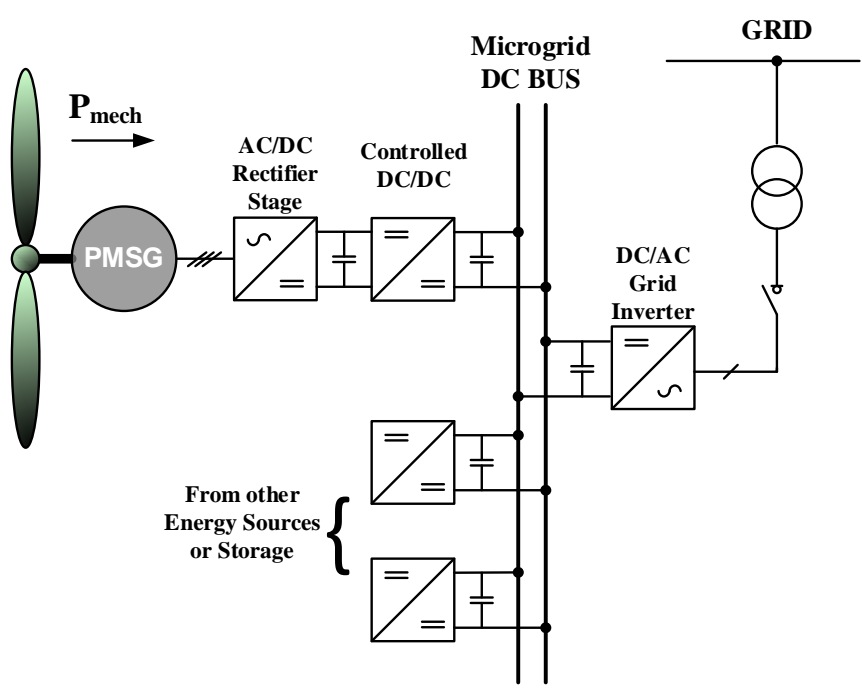

Figure 3. Small Wind Turbine connected to a DC Microgrid.

The considered DC microgrid setup is shown in Fig.3. For the case being considered in this paper, the microgrid is assumed It is assumed to be operating in grid-connected mode through the Grid Inverter. The SWT consists of a $5 \mathrm{~kW}$ PMSG feeding a 3-phase rectifier whose DC output voltage is controlled via a DC/DC converter. The latter converter consisted of a boost topology which was used to interface the rectifier output to the DC microgrid. The boost converter was controlled to obtain maximum power from the SWT into the DC grid. 
A. FMA Analysis of the PMSG

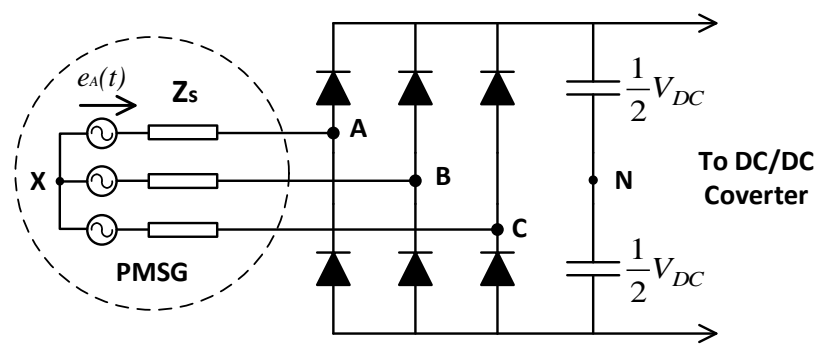

Figure 4. PMSG Feeding Three Phase Rectifier with large DC Link Capacitance

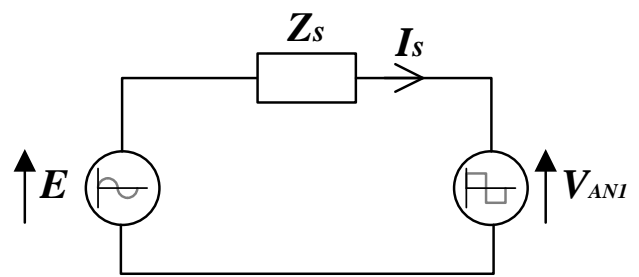

Figure 5. FMA Single Phase Equivalent Circuit for PMSG with capacitive three phase rectifier.

Fig. 4 shows the most commonly used topology for the rectification of PMSGs used in small wind turbines. The three phase diode rectifier normally has a largely capacitive DC link which determines the voltage across the PMSG's terminals. Fig. 5 shows the equivalent single phase circuit of the PMSG after applying fundamental mode approximation (FMA) to the terminal voltage phasor $\boldsymbol{V}_{A N}$ :

$$
\mathbf{V}_{\mathrm{AN1}}=\mathbf{E}-\mathbf{Z}_{\mathbf{S}} \mathbf{I}_{\mathbf{S}}
$$

where $\mathbf{V}_{\mathbf{A N 1}}$ is the fundamental voltage of the machine, $\mathbf{Z}_{\mathbf{S}}$ is the PMSG impedance, $\mathbf{I}_{\mathbf{S}}$ is the phase current and $\mathbf{E}$ is the back-emf of the machine (proportional to the rotational speed).

The single phase apparent power generated by the PMSG is given by:

$$
\mathbf{S}=\mathbf{V}_{\mathrm{AN} \mathbf{1}} \mathbf{I}_{\mathrm{S}}^{*}
$$

where,

$$
\mathbf{I}_{\mathrm{S}}=\frac{\mathbf{E}-\mathbf{V}_{\mathrm{AN1}}}{\mathbf{Z}_{\mathrm{S}}}
$$

Substituting (7) in (6) it can be shown that the real power component is given by:

$$
P=\frac{V_{A N 1} E \cos \left(\theta_{Z}-\delta\right)}{Z_{s}}-\frac{V_{A N 1}^{2} \cos \left(\theta_{Z}\right)}{Z_{s}}
$$

where $V_{A N 1}$ is the RMS value of the fundamental component of the terminal voltage, $E$ is the RMS value of the back-emf, and $Z_{s}$ is the magnitude of the impedance. $\delta$ is the angle between the back-emf and the terminal voltage and $\theta_{Z}$ is the angle of the PMSG impedance. In the case of low power PMSGs such as those used in small wind turbines, the PMSG impedance normally is predominantly resistive $\left(\theta_{Z} \approx 0\right)$ and the real power can be approximated by:

$$
P=\frac{V_{A N 1}\left(E \cos (\delta)-V_{A N 1}\right)}{Z_{S}}
$$

The total output power for the three phase machine is obtained by multiplying (9) by a factor of 3 . Moreover from (9), one can note that the real power is dependent on the DC link voltage amplitude. The latter shall form the power control basis for the considered PMSG topology.

\section{B. Boost Converter Topology and Control System Design}

The boost converter shown in Fig. 6 is a switching converter that produces a higher average output voltage (DC microgrid voltage $V_{d c g r i d}$ ) than the input voltage (DC link voltage $V_{d c}$ ).

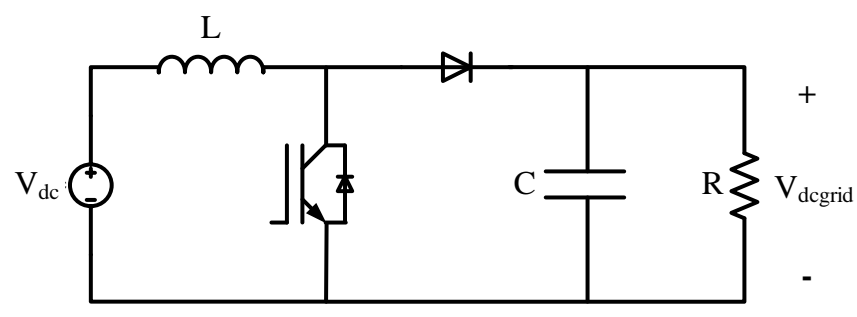

Figure 6. Boost Converter Topology.

For the boost converter, the voltage conversion ratio of the output voltage to the input voltage $(M(D))$, which is a function of the duty cycle $(D)$ is given by:

$$
M(D)=\frac{V_{d c g r i d}}{V_{d c}}=\frac{1}{1-D}
$$

The boost converter inductor $(L)$ value can be found by:

$$
L=\frac{V_{d c} D}{2 \Delta i_{L} f_{s}}
$$

where $\Delta i_{L}$ is the desired inductor current peak ripple and $f_{s}$ is the switching frequency of the boost converter.

The boost converter capacitor $(C)$ value can be found by:

$$
C=\frac{V_{d c g r i d} D}{2 \Delta v_{o} R f_{s}}
$$

where $\Delta v_{o}$ is the desired output voltage peak ripple and $R$ is the load resistance. Since in this particular case $R$ is not used in the simulation, it can be considered as the minimum load resistance to ensure Continuous Conduction Mode (CCM) operation of the converter.

To design the PI current controller, the transfer function of the duty cycle to the inductor current $G_{i d}(s)$ should be used. This transfer function can be obtained by using the small signal equivalent circuit of the boost converter. The derivation of the boost converter small signal equivalent circuit and the transfer function are covered in [8]. In this 
case, the boost converter is being operated within a DC microgrid which is operated in grid-connected through the inverter. Hence, the transfer function of the duty cycle to the inductor current $G_{i d}(s)$ can be reduced to:

$$
G_{i d}(s)=\frac{\hat{i}_{L}(s)}{\hat{d}}=\frac{V_{o}}{s L+R_{L}}
$$

where $\hat{i}_{L}(t)$ and $\hat{d}$ are small ac variations around the quiescent values for the inductor current and duty cycle, respectively. $L$ and $R_{L}$ are the inductance of the boost inductor and the inductor resistance, respectively.

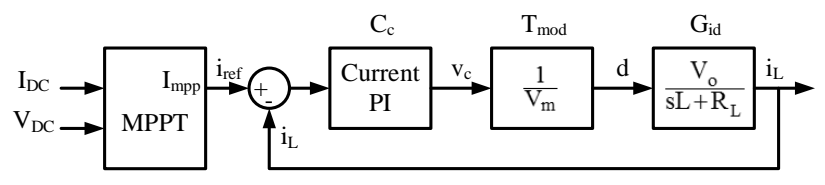

Figure 7. Block Diagram of the boost converter Control System

Fig. 7 shows the block diagram of the control system including the MPPT block. The control system consists of a PI controller to control the inductor current, whose current reference value is obtained from the MPPT system. The MPPT algorithm uses the DC link current and voltage, $I_{d c}$ and $V_{d c}$, respectively, as its inputs to provide the required MPPT current $I_{m p p}$ as an output. The current $I_{m p p}$ is used as the reference current, $i_{r e f}$, to the current controller. In this paper, the DC link is being defined as the connection between the rectifier output and the boost converter input.

The current PI controller, $C_{i}(\mathrm{~s})$ is of the form:

$$
C_{i}(s)=K_{p}+\frac{K_{I}}{s}
$$

where, $K_{P}$ is the proportional gain term and $K_{I}$ is the integral gain term.

The plant transfer function $P_{i}(s)$ for the current PI controller is obtained by:

$$
P_{i}(s)=T_{\text {mod }} \times G_{i d}(s)
$$

where, $T_{\text {mod }}$ is the transfer function representing the pulse width modulation stage.

The pulse width modulation stage produces the duty cycle $d$ that is proportional to the control voltage $v_{c}$. The pulse width modulator makes a comparison between the control voltage $v_{c}$ and a sawtooth waveform with a peak to peak amplitude $V_{m}$. The value for $V_{m}$ is selected by the designer. The frequency of the sawtooth waveform corresponds to the desired converter switching frequency $f_{s}$. The pulse width modulation stage can be modelled by the transfer function $T_{\text {mod }}$ given by:

$$
T_{\text {mod }}=\frac{1}{V_{m}}
$$

The design of the boost converter as shown in Fig. 6 was done using (10), (11) and (12) to find the duty cycle $D$, the inductor $L$ and the capacitor $C$, respectively [8]. The predefined set parameters and the calculated values are shown in Table 1 . The inductor resistance $R_{L}$ and the equivalent series resistance (ESR) of the capacitor $R_{c}$ were taken from actual inductor and capacitor datasheets.

The plant transfer function $P_{i}(s)$ was used to design the current PI controller gains in Matlab. The value for $V_{m}$ was selected to be $440 \mathrm{~V}$, a value larger than the maximum voltage in the system, in this case the DC microgrid voltage of $400 \mathrm{~V}$. The values for the proportional gain term $K_{P}$ and the integral term $K_{I}$ for the current PI controller are 23.76 and 880 , respectively. The bandwidth for the current closed loop which was designed was of $104 \mathrm{~Hz}$.

TABLE I. BOOST CONVERTER PARAMETERS

\begin{tabular}{|l|c|}
\hline \multicolumn{2}{|c|}{ Set Parameters } \\
\hline Input Voltage (DC Link Voltage) $V_{d c}$ & $50-339 \mathrm{~V}$ \\
\hline Output Voltage (DC Grid Voltage) $V_{d c g r i d}$ & $400 \mathrm{~V}$ \\
\hline Switching Frequency $f_{s}$ & $10 \mathrm{kHz}$ \\
\hline Converter Power $P$ & $5 \mathrm{~kW}$ \\
\hline $\begin{array}{l}\text { Inductor current peak to peak percentage ripple } \\
2 \Delta i_{L}\end{array}$ & $0.01 \%$ \\
\hline Output voltage peak percentage ripple $\Delta v_{o}$ & $0.5 \%$ \\
\hline Inductor Resistance $R_{L}$ & $0.002 \Omega$ \\
\hline ESR of Capacitor $R_{C}$ & $0.03 \Omega$ \\
\hline \multicolumn{2}{|c}{ Calculated Values } \\
\hline Duty Cycle $D$ & $0.153-0.875$ \\
\hline Inductor $L$ & $35 \mathrm{mH}$ \\
\hline Capacitor $C$ & $550 \mu \mathrm{F}$ \\
\hline
\end{tabular}

\section{MPPT Algorithm for Small Wind Turbine}

The proposed algorithm only requires power output measurement for operation. This can be readily achieved from the DC link's current and voltage without requiring any speed or wind measurements. Maximum power operation for a wind turbine occurs when:

$$
\frac{d P}{d \omega}=0
$$

Moreover the back-emf of a PMSG is proportional to the rotational speed, $\omega$, and hence it can be shown that:

$$
\frac{d P}{d V_{d c}}=0
$$

where $V_{d c}$ is the DC link voltage which is proportional to the amplitude of the PMSG's terminal voltage. Therefore, the power difference $d P$ can be used to determine the need to increase or decrease the DC link voltage and consequently the DC link current to obtain the maximum power at that particular wind speed.

Fig. 8 shows the flowchart of the MPPT algorithm used in the simulations presented in this paper. This algorithm obtains 
maximum power by calculating the required current value $I_{M P P}$ at that particular wind speed. $I_{M P P}$ is then used as the reference for the current PI controller. The MPPT algorithm increases or decreases the internal reference MPPT voltage $V_{M P P}$ in steps according to the increase or decrease in the DC link power $P_{D C}$. The selection of the step size constant $\Delta V$ is very important. A too small step size causes the MPPT algorithm to take longer to track the maximum power point. On the other hand, a large step size, although it accelerates the tracking, causes larger oscillations around the steady state operating point [2]. Therefore, a compromise for the step size value should be found between fast tracking and minimized oscillations.

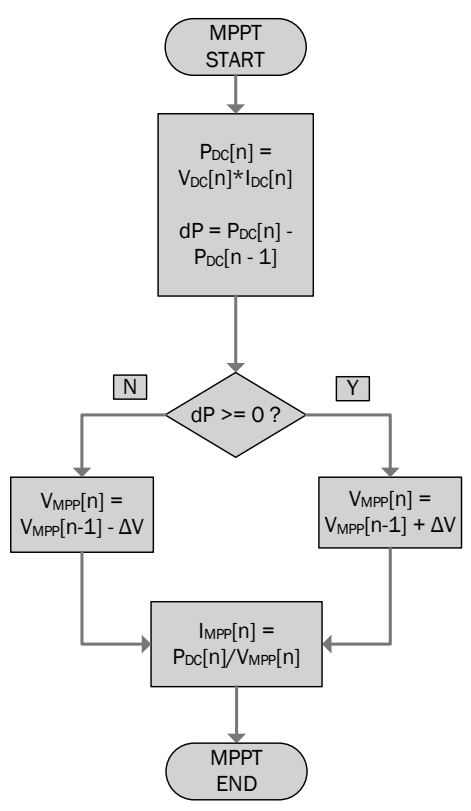

Figure 8. Flowchart of MPPT Algorithm for SWT boost converter

\section{SIMULATIONS}

Simulation of the Microgrid system was carried out for a $5 \mathrm{~kW}$ microwind turbine whose parameters are given in Table 2. The wind turbine including the PMSG and the Boost converter were modelled in Simulink, and are shown in Fig. 9. The simulation considered the operation of the SWT with the microgrid operating at a fixed DC voltage $V_{d c g r i d}$ of $400 \mathrm{~V}$ under grid-connected conditions and with varying wind speed conditions. A typical wind speed profile from $6 \mathrm{~m} / \mathrm{s}$ to $12 \mathrm{~m} / \mathrm{s}$ was provided to the wind turbine model with steps in wind speeds, shown in Fig. 10. Although a step change is not representative of actual wind speed changes, it provides the worst case for the tracking algorithm. The voltage step size constant $\Delta V$ was selected to be 0.1 . The PWM frequency was set to $10 \mathrm{kHz}$.
TABLE II. PMSG AND SWT PARAMETERS

\begin{tabular}{|l|c|}
\hline \multicolumn{2}{|c|}{ PMSG Parameters } \\
\hline Rated Power & $5 \mathrm{~kW}$ \\
\hline Stator Resistance $R_{s}$ & $1.95 \Omega$ \\
\hline Stator Inductance $L_{\mathrm{s}}$ & $1.9 \mathrm{mH}$ \\
\hline Number of pole pairs & 15 \\
\hline Rated Speed & $200 \mathrm{rpm}$ \\
\hline System Inertia & $1 \mathrm{~kg} / \mathrm{m}^{2}$ \\
\hline Viscous Damping SWT Parameters & $0.024 \mathrm{Nms}$ \\
\hline & \\
\hline Cut-in Wind Speed & $2.5 \mathrm{~m} / \mathrm{s}$ \\
\hline Rated Wind Speed & $12 \mathrm{~m} / \mathrm{s}$ \\
\hline Rotor Diameter & $5.5 \mathrm{~m}$ \\
\hline
\end{tabular}

The simulation results for the DC link output power, the DC link voltage, the DC link current, and the PSMG rotor speed are shown in Figs. 11 up to 14. These results show the attainment of maximum power transfer as the wind speed varies using the proposed MPPT algorithm. Fig. 11 shows the DC link output power. At wind speeds of $6 \mathrm{~m} / \mathrm{s}, 8 \mathrm{~m} / \mathrm{s}$ and $10 \mathrm{~m} / \mathrm{s}$, the output power achieved was about $700 \mathrm{~W}, 1.84 \mathrm{~kW}$ and $3.3 \mathrm{~kW}$, respectively. The rated power of the PMSG was reached with a wind speed of $12 \mathrm{~m} / \mathrm{s}$, as expected, delivering a DC link power of 5kW. Fig. 12 shows how the DC link voltage before the boost converter changes with wind speed, while Fig. 13. shows the changes in the DC link current. As explained in section 3 , the current reference is increased/decreased according to the increase/decrease of the DC link power. Fig. 14 shows the corresponding PMSG rotor speed for the above conditions. Fig. 15 and Fig. 16 show the distortion in the stator phase current and the line terminal voltage of the PMSG, respectively.

\section{CONCLUSION}

The paper presented an MPPT algorithm to obtain the optimal power operation of a small wind turbine connected to a DC microgrid under grid-connection conditions. The system consisting of a PMSG driven by a SWT was interfaced to the grid-connected DC microgrid through a rectification stage and a boost converter. The MPPT algorithm proposed is based on the power-speed characteristic of the wind turbine system but is independent of the system parameters. The proposed MPPT algorithm controls the boost inductor current according to variations in the DC link power, to obtain maximum power output. This algorithm was successfully implemented in the simulation model, and simulations for varying wind speeds from $6 \mathrm{~m} / \mathrm{s}$ to $12 \mathrm{~m} / \mathrm{s}$ were carried out. The boost converter allowed for successful transfer of energy from a DC link voltage of around $200 \mathrm{~V}$ to a fixed microgrid voltage of $400 \mathrm{~V}$, with a varying DC link current of around 3.5A to 25A.

The simulation results showed that the optimal power point 
TUrbWind 2017 (Research and Innovation on Wind Energy Exploitation in Urban Environment) Colloquium, Riva del Garda, Italy, 15-16 June 2017

operation was achieved for all wind speeds. This tracking algorithm provided maximum power output into the DC microgrid under all conditions.

\section{REFERENCES}

[1] I. Kortabarria, J. Andreu, I. Martínez de Alegría, J. Jimenez, J. Ignacio Garate, E. Robles, "A novel adaptative maximum power point tracking algorithm for small wind turbines”, Renewable Energy, Volume 63, Pages 785-796, March 2014.

[2] R. Kot, M. Rolak, M. Malinowski, "Comparison of maximum peak power tracking algorithms for a small wind turbine,” Elsevier Journal in Mathematics and Computers in Simulation, Vol. 91 pp. 29-40, 2013.

[3] R. Aubrée, F. Auger and Ping Dai, "A new low-cost sensorless MPPT algorithm for small wind turbines," 2012 First International Conference on Renewable Energies and Vehicular Technology, Hammamet, pp. 305-31, 2012.
[4] M.A. Abdullaha, A.H.M. Yatima, C.W. Tana and R. Saidurb, “A review of maximum power point tracking algorithms for wind energy systems," Renewable and Sustainable Energy Reviews, Vol. 16, Issue 5, pp 3220-3227, June 2012.

[5] D. Zammit, C. Spiteri Staines, A. Micallef, M. Apap," Optimal Power Control for a PMSG Small Wind Turbine in a Grid-Connected DC Microgrid", unpublished.

[6] T. Burton, D. Sharpe, N. Jenkins, and E. A. Bossanyi, Wind Energy Handbook, 2 ed.: John Wiley \& Sons Ltd, 2001.

[7] J. F. Manwell, J. G. McGowan, and A. L. Rogers, Wind Energy Explained, 1 ed.: John Wiley \& Sons Ltd, 2002.

[8] D. Zammit, C. Spiteri Staines, M. Apap, A. Micallef, "Overview of Buck and Boost converters modelling and control for stand-alone DC microgrid operation", Offshore Energy \& Storage Symposium (OSES 2016), Valletta, Malta, July 2016.

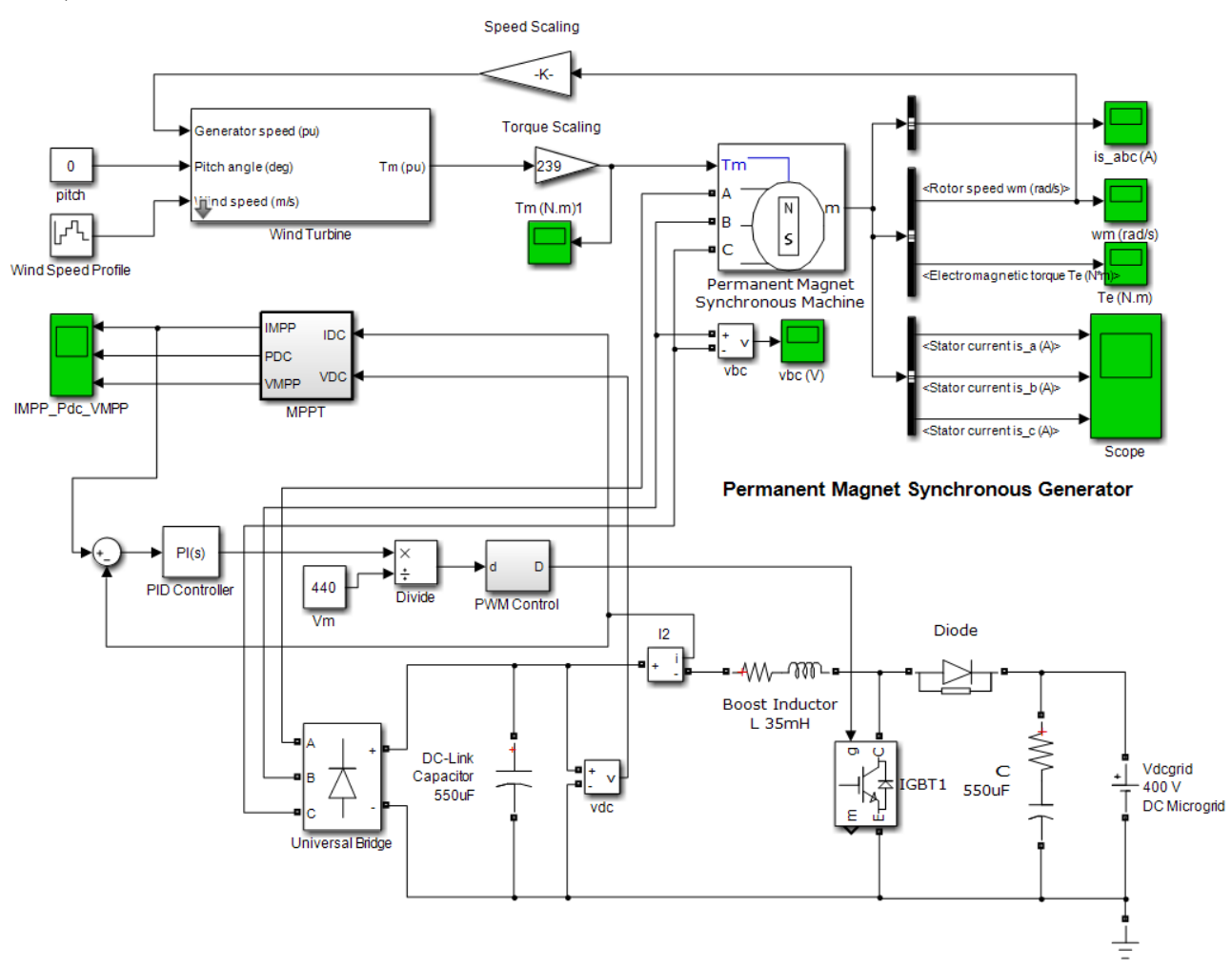

Figure 9. Wind Turbine including PMSG and Boost Converter Simulink Model

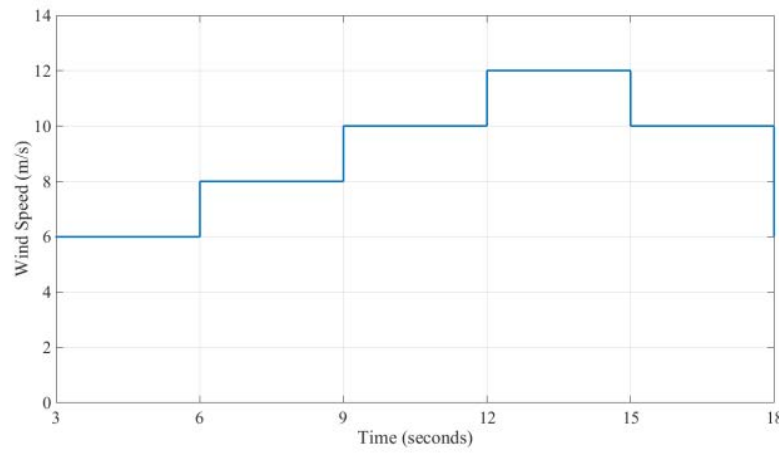

Figure 10. Wind Speed Profile

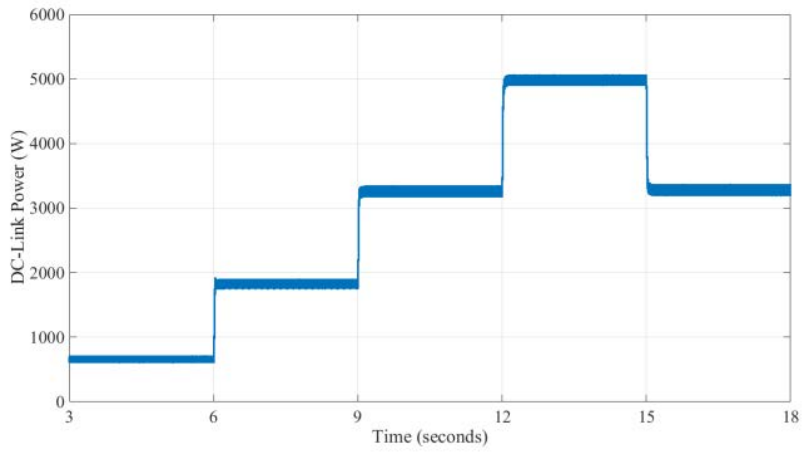

Figure 11. DC Link Output Power 
TUrbWind 2017 (Research and Innovation on Wind Energy Exploitation in Urban Environment) Colloquium, Riva del Garda, Italy, 15-16 June 2017

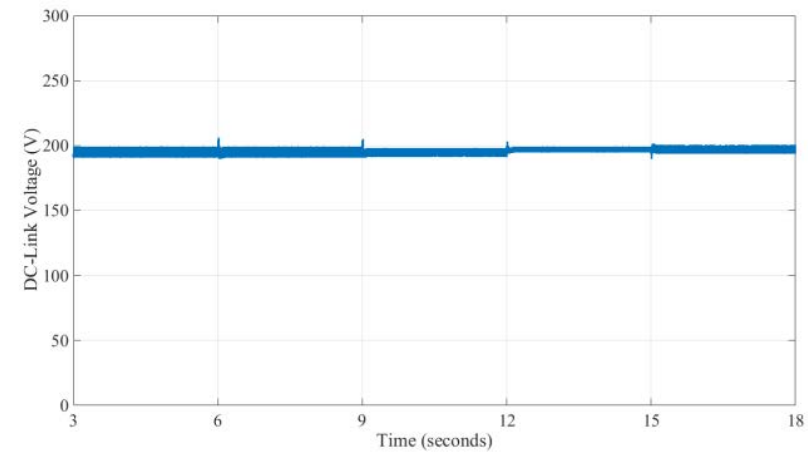

Figure 12. DC Link Voltage

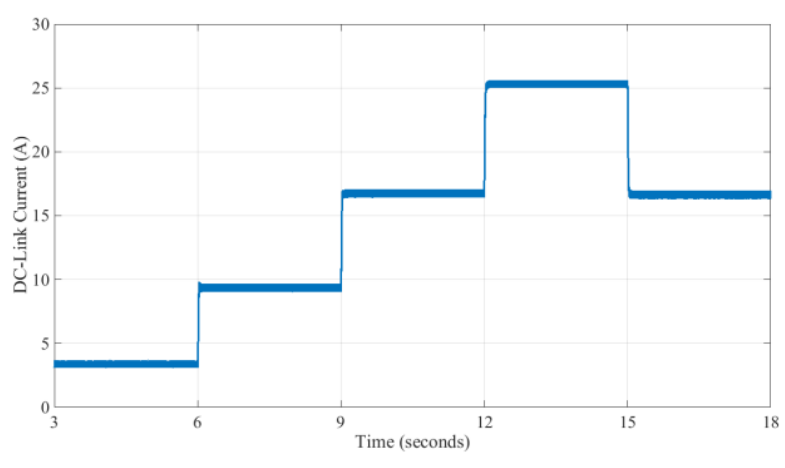

Figure 13. DC Link Current

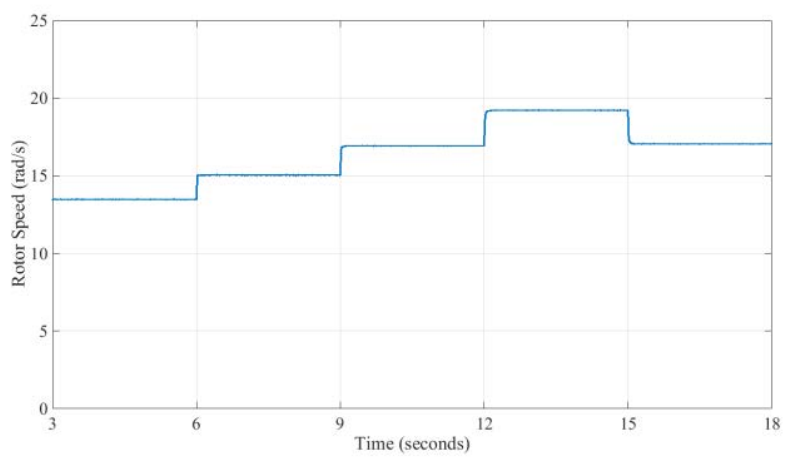

Figure 14. PMSG Rotor Speed

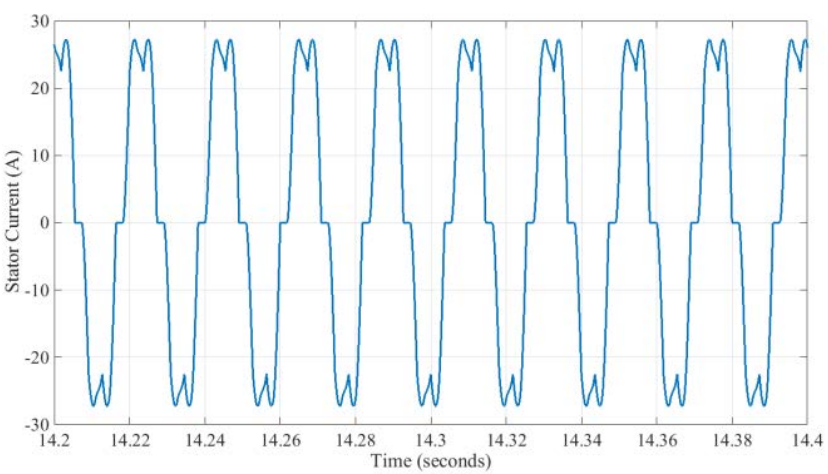

Figure 15. PMSG Stator Current $\mathrm{I}_{\mathrm{a}}$

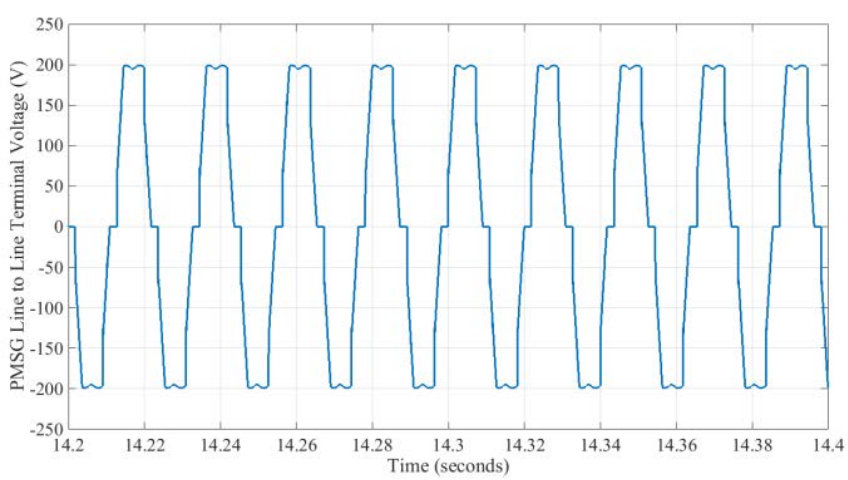

Figure 16. PMSG Line to Line Terminal Voltage 